\title{
Três novas espécies de abelhas da Amazônia pertencentes ao gênero Eulaema (Hymenoptera: Apidae: Euglossini)
}

\author{
Marcio Luiz de OLIVEIRA
}

\section{RESUMO}

Eulaema (Apeulaema) pseudocingulata sp. n., semelhante a E. (A.) cingulata (Fabricius, 1804) e com distribuição pela Amazônia e planalto das Guianas; Eulaem a (Eulaema) parapolyzona sp. n., semelhante a Eulaema (Eulaema) polyzona (Mocsáry, 1897) e exclusiva da Amazônia ocidental, e Eulaema (Eulaema) napensis sp. n., endêmica da Amazônia equatoriana são descritas. Uma chave para identificação das espécies do gênero é apresentada.

\section{PALAVRAS-CHAVE}

Abelhas das orquídeas, Amazônia, novos táxons.

\section{Three new species of Amazonian bees belonging to the genus Eulaema (Hymenoptera: Apidae: Euglossini)}

\section{ABSTRACT}

Eulaema (Apeulaema) pseudocingulata sp. n., similar to E. (A.) cingulata and from Amazonia and Guyana highlands; Eulaema (Eulaema) parapolyzona sp. n., similar to Eulaema (Eulaema) polyzona and from Western Amazonia, and Eulaema (Eulaema) napensis sp. n., endemic of Ecuatorian Amazonia are described. A key for species identification of the genus is presented.

\section{KEYWORDS}

Orchid bees, Amazonia, new taxa

\footnotetext{
${ }^{1}$ Instituto Nacional de Pesquisas da Amazônia. Coordenação de Pesquisas em Entomologia. Av. André Araújo 2936. Petrópolis. Caixa postal 478 Manaus AM. Brasil.69011-970. mlolivei@inpa.gov.br
} 


\section{ACTA \\ AMAZONICA}

TRÊS NOVAS ESPÉCIES DE ABELHAS DA AMAZÔNIA PERTENCENTES AO GÊNERO Eulaema (HYMENOPTERA: APIDAE: EUGLOSSINI)

\section{INTRODUÇÃO}

A tribo Euglossini é exclusiva da região Neotropical, compreendendo cinco gêneros e quase duas centenas de espécies de abelhas conhecidas como "abelhas das orquídeas", pelo fato de muitas espécies de orquídeas nessa região serem polinizadas exclusivamente por machos dessa tribo.

Neste trabalho são reconhecidas 26 espécies para o gênero Eulaema Lepeletier, 1841, cujo tamanho varia de 20 a $30 \mathrm{~mm}$, com pilosidade relativamente densa e com o tegumento desprovido de brilho metálico na cabeça e no mesossoma (Oliveira, 2000). Moure (2000) apresenta um catálogo onde faz comentários sobre os tipos descritos por outros autores e descreve quatro novas espécies: Eulaema basicincta, E. belvola, E. pallescens e E. stenozona, sendo que as duas últimas são aqui consideradas sinônimos de $E$. meriana e $E$. terminata, respectivamente. Além disso, as seguintes espécies consideradas válidas por Moure (2000) também são consideradas sinônimos: E. quadrifasciata $($ Friese, 1903) $=$ E. meriana (Olivier, 1789); E. mimetica Moure, $1967=$ E. tenuifasciata (Friese, 1925); E. niveofasciata $($ Friese, 1899) $=$ E. bombiformis (Packard, 1869).

Este trabalho faz parte de uma ampla revisão das espécies do gênero (Oliveira, $o p$. cit.), onde foram examinados cerca de 4.000 exemplares cobrindo toda a região neotropical.

\section{MATERIAL E MÉTODOS}

Em Material Examinado, os dados estão como nas etiquetas dos exemplares examinados, salvo o que estiver entre colchetes. Onde aparece "???", significa que a localidade de coleta não pôde ser localizada em nenhum estado, departamento ou província. O material examinado pertence às seguintes instituições: AMNH - American Museum of Natural History, New York, Jerome Rozen; CJBB - Jardim Botânico de Brasília e CUNB - Universidade de Brasília, Antony Raw; CMLO - Coleção do autor; CMNH - The Carnegie Museum of Natural History, Pittsburg, Robert Davidson; CPCS - Clemens Schlindwein; CPDD - Domiciano Dias; CPGM - Gabriel A. R. Melo; CPSM - Sidney Mateus; CUIC - Cornell University Insect Collection, Ithaca, E.R. Hoebeke; MNRJ - Museu Nacional do Rio de Janeiro, Miguel A. Monné; MPEG - Museu Paraense Emílio Goeldi, Belém, Ana Y. Harada; MRSN - Museo Regionale di Scienze Naturali, Torino, P.L. Scaramozzino; MZSP - Museu de Zoologia da Universidade de São Paulo, Carlos R. F. Brandão; MZUP - Museu de Zoologia, Universidade Federal do Paraná, Curitiba, Germano H. R. Neto; NhMW - Naturhistorisches Museum of Wien, Stefan Schodl; NZCS - National Zoological Collection of Suriname, Panamaribo, Helene Hiwatt van Laar; QCAZ- Museo de Zoologia de la Universidad Católica de Quito, Giovanni Onore; RPSP - Faculdade de Filosofia, Ciências e Letras/ USP, Ribeirão Preto, João M.F. Camargo; SEAN - Servicio Entomologico Autonomo, Leon, Nicaragua, Jean Michel Maes; SEMK - Snow Entomological Museum of Kansas, Lawrence, Robert Brooks; UCDC - University of California, Davis, S.L. Heidon; UFMA - Universidade Federal do Maranhão, São Luís,
Márcia Rego; UFMG - Universidade Federal de Minas Gerais, Belo Horizonte, Fernando Amaral da Silveira; UFPE Universidade Federal de Pernambuco, Recife, Isabel Machado; UFVB - Universidade Federal de Viçosa, Lúcio A. O. Campos; UNCB - Universidad Nacional da Colombia, Bogotá, Guiomar Nates Parra; UPJP - Universidade Federal da Paraíba, João Pessoa, Celso Feitosa Martins; UPPt - Universidade Federal de Campina Grande, Patos, Fernando C. V. Zanella; ZMUC - Zoological Museum, University of Copenhagem, Rudolf Meier; ZSMC Zoologische Staatssammlung, Munique, Johannes Schubert.

\section{RESULTADOS E DISCUSSÃO}

\section{Eulaema (Apeulaema) pseudocingulata sp. $\mathrm{n}$.}

Eulaema (Apeulaema) cingulata; Moure, 1960. Studia Ent., 3: 99, 145.46 (Tax., Syn., Redescr., DGeogr., partim). - Moure, 1963, Rev. Biol. Trop. 11(2): 212 (Ch., DGeogr., partim). Urban, 1963, Bol. Univ. Paraná,Zool. 2 (2): 21, 31 (Cat., Morf., partim). - Bennett, 1965, Ins. Soc. 12(1): 81,82 (Nid., partim). - Sakagami \& Michener, 1965, Annot. Zool. Japonenses 38(4): 221-222, figs. 13 e 14 (Nid., partim). Moure, 1967, Atas Simp. Biota Amazônica, Zool. 5: 411 (Cat., partim). - Moure, 2000, Acta Biol. Par., 29:22 (partim).

Eulaema cingulata; Dodson, 1962, Bull. Amer. Orchid. Soc. 31 (reprint): 4, 5, 16, 21, fig. 9 (Flor., DGeogr., partim). -Dodson, 1965, Bull. Amer. Orchid. Soc. 681, 684 (Flor., DGeogr., partim). - Cruz-Landin et. al., 1965, Rev. Bras. Biol. 25(4) 323 (Morf.,partim) . - Vogel, 1966, Osterreich, Bot. Zeitschr. 113 (Heft $3 / 4$ ): 306, 310, 344-6, 354-6 (Morf. Biol., DGeogr., partim). - Dressler, 1967, Atas Simp. Biota Amazônica, Zool. 5: 174. - Dressler, 1968, Rev. Biol. Trop. 15(1): 148-159 (D.Geogr., Biol., Flor., partim). - Dressler, 1968, Evolution, 22: 203-208, fig. 1 (Pol., partim). - Jansen, 1971, Science, 171: 204 (Biol., partim). - Bennett, 1972, J. N. Y. Ent. Soc. 80(3): 141, 142, 144 (Biol., partim). - Dressler, 1979, Biotropica 11(2): 150 (Ch., partim).- Kimsey \& Dressler, 1986, Pan-Pacific Ent. 62(3): 234 (Cat., partim). -González, 1998, Bol. Centro Invest. Biol. 32(3): 205-209 (Atrat., Flor., DGeogr.,partim) -Ospina-Torres, 1998, Rev. Biol. Trop. 46(3): 751, 753, 761, fig. 9 (Morf., Tax., Ch., partim) . - Ramírez, Dressler \& Ospina, 2002, Biota Colomb. 3(1): 24, 29, 32, 8691 (Biol., DGeogr, Flor., partim).

Eulaema pseudocingulata; Nemésio \& Morato, 2004, Rev. Tecnol. eAmbiente 10(2): 75-76 (N. nudum).

Diagnose: Área aveludada da tíbia média longa e estreita, afastada do bordo posterior e deixando aí uma extensa área lisa (Fig. 1f); coxim basal longo, estreito e levemente inclinado; labro com carenas laterais levemente encurvadas no ápice $e$ terminando bem antes do bordo do clípeo, a carena média bem mais curta que estas.

Etimologia: Relacionada ao fato dessa espécie ser muito semelhante a $E$. (A) cingulata, sendo facilmente confundidas. 


\section{ACTA AMAZONICA}

TRÊS NOVAS ESPÉCIES DE ABELHAS DA AMAZÔNIA PERTENCENTES AO GÊNERO Eulaema (HYMENOPTERA: APIDAE: EUGLOSSINI)

Medidas: Comprimento total $22 \mathrm{~mm}$; comprimento das asas anteriores $18 \mathrm{~mm}$; largura do mesossoma $7 \mathrm{~mm}$, largura da cabeça $6 \mathrm{~mm}$, comprimento da cabeça $5 \mathrm{~mm}$; comprimento da língua $12 \mathrm{~mm}$.

Coloração: Tegumento da cabeça, mesossoma, tergos e tíbias posteriores castanho-escuro e sem reflexos metálicos; castanho-claro no esternos I-IV e demais pernas; castanhoamarelado no sexto esterno; clípeo com desenhos amarelados em forma de âncora, manchinhas amarelas nas áreas supraclipeal e para-oculares; asas muito escuras e muito pouco transparentes na base junto às tégulas, mas de um âmbar-claro e transparente no restante.

Pilosidade: Alaranjada escura nos tergos, exceto no segundo que possui a metade basal formada de pêlos pretos; pilosidade preta e abundante no mesossoma, escassa na cabeça; amarelada nos bordos laterais dos esternos; cerdas dos esternos II-IV com a extremidade curvada para dentro; no quinto para fora; no sexto ausente; tíbia posterior com pêlos curtos e claros na face externa e no interior da fenda tibial, porém pretos na franja situada após a fenda tibial; pilosidade da face externa da tíbia posterior longa anteriormente e curta no restante; muito curta e preta na área aveludada e coxim; cerdas dos basitarsos posteriores tão longas quanto a maior largura dos mesmos.

Pontuação: Superficial, esparsa e de diferentes tamanhos na face; densa de tamanho pequeno no vértice; pouco profunda e esparsa na face externa das tíbias posteriores.

Tipo: Holótipo, macho com os seguintes dados "Brasil,

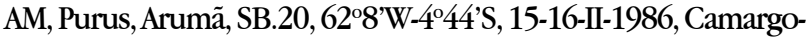
Mazucato leg., det. Moure, 1987 [como E. (Apeulaema) cingulata (Fabricius, 1804)], n ${ }^{\circ}$ 862271" (RPSP). Fêmea desconhecida. Parátipos: Rio Purus, Rio Ipixuna, SB20, 6320'W/60'S, 20,23.I.1986, nº 860594, Camargo-Mazucato leg., 1 macho, det. Moure, 1987 [como "Eulaema cingulata"], [etiqueta adicional] (RPSP); idem, Arimã, SB.20, 63\%41'W-5\%43'S, 3,8-II-1986, Camargo-Mazucato leg, 1 macho, n ${ }^{\circ} 861515$, idem (RPSP); idem, Rio Ipixuna, SB.20, 6325'W - 6 ${ }^{\circ}$ 'S, 16,19-I1986, idem, 1 macho, $\mathrm{n}^{\circ} 860038$, idem (RPSP); idem, Paricatuba,

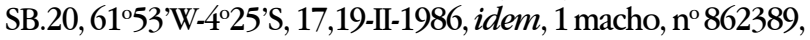
idem, (RPSP); Manaus, VIII-58, C. Elias leg., 1 macho, idem (RPSP); Rio Juruá, Carauari, 20-24.07.1993, 66 ${ }^{\circ} 54^{\prime}$ W/4º53'S, Camargo, Pedro \& Mazucato leg., 2 machos, nos. 932675 e 932676, det. Macário, 1993 [como "Eulaema cingulata"] (RPSP).

\section{Material adicional examinado}

TRINIDAD \& TOBAGO. Localidade não citada, data não citada, Sem dados do coletor, 1 macho, $\mathrm{n}^{\circ} 418$, Collection J. Angus, [etiqueta adicional] (AMNH); Arima Valley, B.W.I., 28-XII1952, Sem dados do coletor, 1 macho, Gift of New York Zoo. Soc. Dept. Tropical Research, William Beebe dir., [etiqueta adicional] (AMNH). VENEZUELA. Miranda: TFA/Rio Gavilan, Köder: p-Dimethoxybenzen, 12/92, coll.Gerlach, 1 macho, GG38 (ZSSM). Barinas: Barinitas, Köder: [não citada], 3/93, coll. Gerlach, 1 macho, GG-304, poll.: Gongora (ZSSM). Amazonas:
TFA/Pto. Ayacucho, Köder: [não citada], 9/92, coll. Gomez, 3 machos, GG-223, GG-226, e GG-232 (ZSSM). GUIANA. DemeraraMahaica: Georgetown, III. 1995, M. Alvarenga legit, 1 macho, Coleção Campos Seabra, [etiqueta adicional] (SEMK). SURINAME. Wanica: Paramaribo, Bot. Gard., 22.VII.1941, Geijskes [sic] leg., 1 macho e Botanical Garden, EQ.6/, 22 Jul 1941, D.C. Geyskes [sic] leg., 1 macho, ${ }^{\circ}$ I 1848: d), det. D.C. Geyskes [sic] sem data [como "Eulaema cingulata"], [etiqueta manuscrita original e etiquetas novas impressas] (NZCS). Commewijne: Oost-westverbinding-road, 21-25Km E of Com..., SME Q.Q 15, 08 Jan 1997-22 Jan 1997, B. de Dijn ea. leg., 2 machos, $\mathrm{n}^{\circ}$ I 1927: d), idem [etiqueta adicional] (NZCS). Marowijne: Langaman Kondre, VIII-15-22-1965, Borys Malkin leg., 2 machos [etiqueta adicional] (AMNH). Sipaliwini: Sipaliwini, forest near Sipaliwini creek,...SME Q.Q100, 13 Apr 1997-16 Apr 1997, H. Hiwat ea. leg., 2 machos, nos. I 1907d, I 1908d, det. H. Hiwat ea., sem data, [como "Eulaema cingulata"], [etiqueta adicional] (NZCS); idem, on air strip, idem, 1 macho, $\mathrm{n}^{\circ}$ I 1925: d), idem, [etiqueta adicional] (NZCS). GUIANA FRANCESA. Caen: Kourou, 16Km SW, 13. Apri. 1977, D. Roubik leg., 1 macho, ${ }^{\circ} 127$ (SEMK); idem, $11.5 \mathrm{Km} \mathrm{SW,} 11$. July. 1977, C.D. Michener leg., 1 macho (SEMK); idem, 6 Km SW, 13. July. 1977, idem, 1 macho, det. R.L. Dressler, sem data [como "Eulaema cingulata"] (SEMK); Cayenne, $47 \mathrm{Km} \mathrm{S,} 23$. Feb. 1977, C.D. Michener, M. Winston \& G. Otis leg., 1 macho (SEMK); Tonate, 22. Nov. 1976, M. Winston \& G. Otis leg., 1 macho (SEMK). PERU. Loreto: Iquitos, data não citadae VI.23.24, Sem dados do coletor, 2 machos, nos. F6062 e F.6063, H. Bassler Collection, Acc 33591 (AMNH). Ucayali: Pucalpa [sic] III.6-1966, J. Schunke leg., 1 macho (AMNH). BRASIL. Amazonas: Benjamim Constant, rio Javari, alto Amazonas, Mar 1964, Jul 1960, Dirings leg., 2 machos, [etiqueta adicional manuscrita à lápis] (MZSP); Itacotiara, VIII/1960, Dirings leg., 3 machos (MZSP); Pará: Localidade não citada, 3-1901, Ducke leg., 1 macho, det. Friese, 1909 [como "Euglossa fasciata"], Am. Mus. Nat. Hist. Dept. Invert. Zool. no. 26536, [etiqueta adicional] (AMNH); Belém, sw, data não cit., Domiciano Dias leg., 3 machos, nos. IPEANEU12, IPEANEU12-1, IPEANEU132-1, det. Pe. J.S. Moure, 1968 [como "Eulaema cingulata"] e det. Sakagami, sem data [como "Eulaema cingulata"] (CPDD); idem, 22.I.1964, III.1964, 10.XII.1964, 2.1965, E. Dente leg., 11 machos (MZSP); idem, Reserva Guamá, III.1964, E. Dente leg., 1 macho (MZSP); Rio Trombetas, Lago Carimun, SA-21-X-C, 56ㅇ' W/1 $32^{\circ}$ S, 16,17.II.1979, Camargo leg., 1 macho, det. Moure, 1984 [como "Eulaema cingulata"] (RPSP); Canindé, Rio Gurupi, IV.1963, B. Malkin col., 1 macho, símbolo de macho, [etiqueta adicional] (MZSP); idem, Malkin \& Pinheiros col., 2 machos, símbolo de macho, [etiqueta adicional] (MZSP); Cachimbo, VIII-955, Verner leg., 2 machos, det. Sh. F. Sakagami sem data [um exemplar como "Eulaema cingulata"] (MZSP); Aldeia Yararuhu ("Aracu"), Igarapé Gurupi-Una, Rio Gurupi, II-11-25-1966, Borys Malkin collector, 3 machos, [etiqueta adicional] (AMNH). Acre: Rio Branco, 21/07/1996, 27/07/1996, 09/09/1996, Luz, M.M. leg., 4 machos, nos. 63, 71, 76 e 191, [etiqueta adicional manuscrita] (INPA); Parque Nacional da Serra do Divisor, sítio 1, Trilha do Morro Queimado, 7²6'36"S/7340'28"W, 11/11/1996, E.F. 
Morato leg., 1 macho, $n^{\circ} 970014$ (INPA); idem, sítio 3, Trilha de caça do Sr. Piroca, 7²8'38"S/7341'54"W, 12,13/11/1996, idem, 1 macho, $\mathrm{n}^{\circ} 970090$ (INPA); idem, sítio 5, Igarapé Ramon, 7²7'32"S/73\%46'28", 15-18/11/1996, idem, 1 macho, n' 970030 (INPA). Rondônia: São Miguel do Guaporé, linha 82, 1140.836'S6243.256'W, 22-abr-97, Brown, Boina \& Vieira, 1 macho, RO8164, [etiqueta adicional] (INPA). Maranhão: S. Luis, 16/4/89, 15/10/89, 1/4/8? e 1/4/89, L.F. Gomes leg., 5 machos, nos. 1324, 1828, 1829, 1300, 1301, [etiqueta adicional] (UFMA); idem, 26/ 10/90, Lacerda leg., 1 macho, ${ }^{\circ} 013$, [etiqueta adicional] (UFMA); Alcântara, essência Eg 9-10, 3/1/1993, Brito leg., 1 macho, [etiqueta adicional] (UFMA). Mato Grosso: Barra do Tapirapé, XII-28-1965-I-15-1966, idem, 7 machos, [etiqueta adicional] (AMNH); Nova Mutum, Fazenda Buriti, Estrada Roda D'água, 7/ XII/1997, H. Mendes leg., 1 macho (INPA).

Discussão. Espécie bastante semelhante a E. (A.) cingulata, tendo sido confundida com esta, até então. Podem ser separadas por meio da área aveludada que é bem mais estreita e distante do bordo posterior (Fig. 1f) ao passo que em $E$. cingulata é larga e próxima ao bordo posterior (Fig. 1g). A coloração do abdômen é de um alaranjado mais escuro que em E. (A.) cingulata. Quanto às áreas de distribuição, $E$. (A.) cingulata está amplamente distribuída desde o noroeste do México até a Bolívia e sul do Brasil, ao passo que $E$. (A.) pseudocingulata está restrita à bacia amazônica, Guianas e Venezuela, onde ocorre em simpatria $\operatorname{com} E$. (A.) cingulata.

\section{Eulaema (Eulaema) parapolyzona sp. n.}

Eulaema polyzona; Moure, 1944, Bol. Mus. Javier Prado, Lima 8: 75 (Cat., partim). - Vogel, 1966, Osterreich. Bot. Zeitschr. 113 (3/4): 326, 357 (Dgeogr., Flor., partim). - Dressler, 1979, Biotropica 11(2): 151 (Ch., DGeogr., partim). - Kimsey \& Dressler, 1986, Pan-Pacific Ent. 62(3): 229-236. - OspinaTorres, 1998, Rev. Biol. Trop. 46(3) : 751, 754, 760, 761, fig. 18 (Morf., Ch., partim) . - Ramírez, Dressler \& Ospina, Biota Colomb. 3(1): 24, 29, 100 (Atrat., Tax., DGeogr.,partim).

Eulaema (Eulaema) polyzona; Moure, 1950, Dusenia 1(3): 195.9, 200.-Moure, 1967, Atas Simp. Biota Amazônica, Zool. 5: 412 (Cat., partim). - Moure, 2000, Acta Biol. Paranaense $29(1,2,3,4): 29,53-55$ (Cat., Ch., Tax., DGeogr., Flor., partim).

Diagnose: Carenas laterais do clípeo curtas, atingindo no máximo à metade do mesmo; lisas anteriormente; carenas do labro praticamente retas e convergindo um pouco no ápice, a do meio um pouco menor; área aveludada da tíbia média relativamente longa e pouco afastada do bordo posterior (Fig. 1h); coxim muito mais longo que largo e não inclinado em relação à area aveludada.

Etimologia: Do grego para = ao lado de, por ser espécie muito próxima de $E$. (E.) polyzona e por possuir distribuição geográfica parapátrica com esta.

Medidas: Comprimento total $22 \mathrm{~mm}$; comprimento das asas anteriores $17 \mathrm{~mm}$; largura do mesossoma $8 \mathrm{~mm}$; largura da cabeça 5,5 mm; comprimento da cabeça, 4,5 mm; língua 14 $\mathrm{mm}$.

Coloração: Cabeça, mesossoma e tíbias posteriores castanho escuro; tergos com reflexos metálicos de tonalidade verde escuro; castanho mais claro nos esternos, pernas anteriores e médias; castanho amarelado no sexto esterno; manchas amarelas da face restritas à sutura mediana do clípeo, áreas paraclipeais e supraclipeal.

Pilosidade: Esparsa e escura na cabeça, densa e escura no mesossoma; nos tergos, dividida em faixas, escura no bordo anterior e amarela no posterior; no primeiro tergo a faixa de pêlos escuros é mínima, do segundo ao quarto equivale a mais de $2 / 3$ do comprimento do tergo; do quinto ao sétimo amarelo escuro; cerdas do esternos II-IV grossas e curvadas no ápice; no quinto finíssimas e ralas, no sexto ausentes; cerdas muito longas nos basitarsos posteriores (maiores que a largura do mesmo); na face externa das tíbias posteriores, longas na porção anterior e curtas posteriormente.

Pontuação: Muitos sulcos profundos em lugar de pontos na área ínfero-lateral do clípeo; esparsa, superficial e de pequena a muito pequena no vértice; esparsa e pouco profunda na face externa das tíbias posteriores.

Tipo: Holótipo, macho, de "Bolívia, Chapare, Tropical Reg., 400 mts., 15 August 1950 (Zischka), det. Moure, 1963 [como "Eulaema (Eulaema) polyzona (Mocs.)"] (SEMK). Parátipos e alótipos: EQUADOR. Napo: Coca, on Rio Napo, Napo-Paztaza [sic], V-1965, L.E. Pena collector [etiqueta adicional], 1 macho e 1 fêmea (AMNH); Pompeya, idem, $40 \mathrm{Km}$. from Coca, idem, 1 fêmea, idem (AMNH). PERU. Loreto: Pucallpa, II-16-1967, J. Schunke leg., 1 fêmea (AMNH); Middle Rio Ucayali, X.27.23, Sem dados do coletor, 1 fêmea, ${ }^{\circ}$ F6116, det. J.S. Moure, 1953 [como "Eulaema polyzona"], H. Bassler Collection, Acc 33591, (etiqueta adicional) (SEMK). San Martin: Achinamiza, VIII-2827, Sem dados do coletor, 1 macho, $n^{\circ}$ F6001, det. H.F. Schwarz, sem data [como "Euglossa (Eulaema) polyzona Mocsaryi"], $\mathrm{H}$. Bassler Collection, Acc 33591, [etiqueta adicional] (SEMK). Madre de Dios: Avispas, $156 \mathrm{Km}$. from Puerto Maldonado, IX10-30-1962, L.E. Pena collector, 1 macho, [etiqueta adicional] (AMNH). BOLÍVIA. Beni: Guayaramerin, Rio Mamore, V-1-4-1964, J.K. Bouseman \& J. Lussenhop Collectors, 1 macho, [etiqueta adicional] (AMNH).

\section{Material adicional examinado}

COLÔMBIA. Amazonas: Parque Nacional Amacayacu [sic], Trocha Panduro, 14.1.85, A. Villa leg., 1 fêmea, nos. 102 e 5466, det. M.A. Bonilla SEM DATA [como "Eulaema polyzona"], [etiqueta manuscrita] (UNCB). EQUADOR. Napo: Coca, $350 \mathrm{~m}$, VI-84, G. Onore legit, 1 fêmea, [etiqueta manuscrita parcialmente] (QCAZ); SC Yasuni, 250 m, 01-08 Mar 1997, Itapia leg., 1 macho (QCAZ). ???: Santa Jnéz [sic], data não cit., R. Haensch S. leg., 1 macho, nos. 18.044 e 103.001, $1^{\circ}$ det. Friese, 1904 [como "Eulema [sic] polyzona Mocs."], $2^{\circ}$ det. Sh. F. Sakagami, sem data [como "Eulaema polyzona"], [etiquetas adicionais] (MZSP). PERU. Loreto: Pucallpa, 3 Agosto 1959, 1 


\section{ACTA AMAZONICA}

TRÊS NOVAS ESPÉCIES DE ABELHAS DA AMAZÔNIA PERTENCENTES AO GÊNERO Eulaema (HYMENOPTERA: APIDAE: EUGLOSSINI)
Maio 1959, J.M. Schunke leg., 2 fêmeas, Coleção Campos Seabra, [etiqueta adicional] (MNRJ). Huanuco: Tingo Maria, Outubro 1960, J.M. Schunke leg., 1 fêmea, Coleção Campos Seabra, T.M. 5.10.60, [etiqueta manuscrita], [etiqueta adicional] (MNRJ). Junin: La Merced, Rio Colorado, 900-1100 mts., 20-X-1989, Mielke, Casagrande \& G. Lamas leg., 1 fêmea, [etiqueta adicional] (DZUP) .

Discussão. Espécie bastante semelhante a $E$. (E.) polyzona, não tendo sido percebida até então por outros autores. Entretanto, pode ser separada desta por meio da área aveludada que é mais comprida e semelhante à bainha de facão (Fig. 1h), ao passo que em $E$. (E.) polyzona é mais curta e mais delgada na extremidade (Fig. 1i); o basitarso posterior é mais longo que em E. (E.) polyzona. Asmanchas amareladas na face não foram encontradas nos parátipos examinados, nem em nenhum dos demais exemplares examinados. Esse caráter, que é exclusivo de machos do subgênero Apeulaema, embora possa faltar com freqüência, foi um dos que Moure (1950) utilizou para criar o referido subgênero. No entanto, é a primeira vez que é visto em um representante do subgênero Eulaema. Quanto à distribuição geográfica, E. (E.) polyzona só tem sido coletada na Amazônia central, enquanto Eulaema parapolyzona sp. n. só tem registros para a Amazônia ocidental na Colômbia, Equador, Peru e Bolívia, até as proximidades dos contrafortes dos Andes. Moure (1950), Dressler (1979) e Peruquetti et al. (1999) citam a ocorrência de E. (E.) polyzona, além da bacia Amazônica, também no estado do Espírito Santo, na costa brasileira, o que é um equívoco.

\section{Eulaema (Eulaema) napensis sp. $\mathrm{n}$.}

Tipo: Holótipo, macho, de "Ecuador, Napo, Jumandi, II/ 86, D. Sanchez", QCAZ.

Diagnose: Carena média do clípeo lisa no ápice e saliente; as laterais pouco salientes e curtas, chegando no máximo à metade do clípeo; carenas central e laterais do labro praticamente paralelas e do mesmo tamanho; área aveludada da tíbia média muito longa e estreita; um pouco afastada do bordo posterior da tíbia (Fig. 1e); coxim anterior mais longo que largo, com a extremidade superior delgada e inclinada em relação à área aveludada.

Etimologia: Relativo à província de Napo, Equador, onde o exemplar foi coletado.

Medidas: Comprimento total $17 \mathrm{~mm}$, comprimento das asas anteriores $18 \mathrm{~mm}$; largura do mesossoma $8 \mathrm{~mm}$; largura da cabeça $6 \mathrm{~mm}$; comprimento da cabeça $5 \mathrm{~mm}$; língua $19 \mathrm{~mm}$.

Coloração. Tegumento castanho-escuro na região da cabeça, mesossoma e pernas; face externa das tíbias posteriores e esternos castanho muito escuro; tergos verde-escuros com reflexos metálicos; asas anteriores âmbar-escuro e pouco transparente na metade basal, âmbar-claro no restante.

Pilosidade: Dourada na escova dianteira e franja pós-tibial; negra na fenda tibial; negra, longa e esparsa nas áreas paraoculares e vértice; negra e densíssima no mesossoma; negra, menos densa e menos longa nos tergos I-III; amarelo-clara, longa e pouco densa nos tergos IV-VII; negra, esparsa e relativamente longa na face externa da tíbia posterior; na franja posterior dos basitarsos posteriores igual ou pouco mais curta que a maior largura dos basitarsos; cerdas dos esternos II-IV com as pontas encurvadas para dentro no ápice; retas nos esternos IV-V; ausentes no esterno VI.

Pontuação: Superficial, esparsa e de pequeno tamanho na porção superior do clípeo e áreas paraoculares; mais densa e coalescente na porção inferior; superficial densa e minúscula no vértice; bastante esparsa na face externa da tíbias posteriores.

Discussão. À primeira vista confunde-se com $E$. (E.) leucopyga devido ao fato de possuir pilosidade preta nos três primeiros tergos e amarelada nos demais; mas se separa desta nos seguintes aspectos: é menor, possui a área aveludada longa e delgada (Fig. 1e), que em E. leucopyga é curta e larga (Fig. 1a); as fimbrias posteriores dos basitarsos metatorácicos não são muito longas, sendo iguais ou um pouco mais curtas que a maior largura dos mesmos e possuem os pêlos amarelos mais curtos nos tergos V-VII.

Chave para as espécies do gênero Eulaema (somente machos)

- Tegumento dos tergos metassomáticos preto, marrom, ou

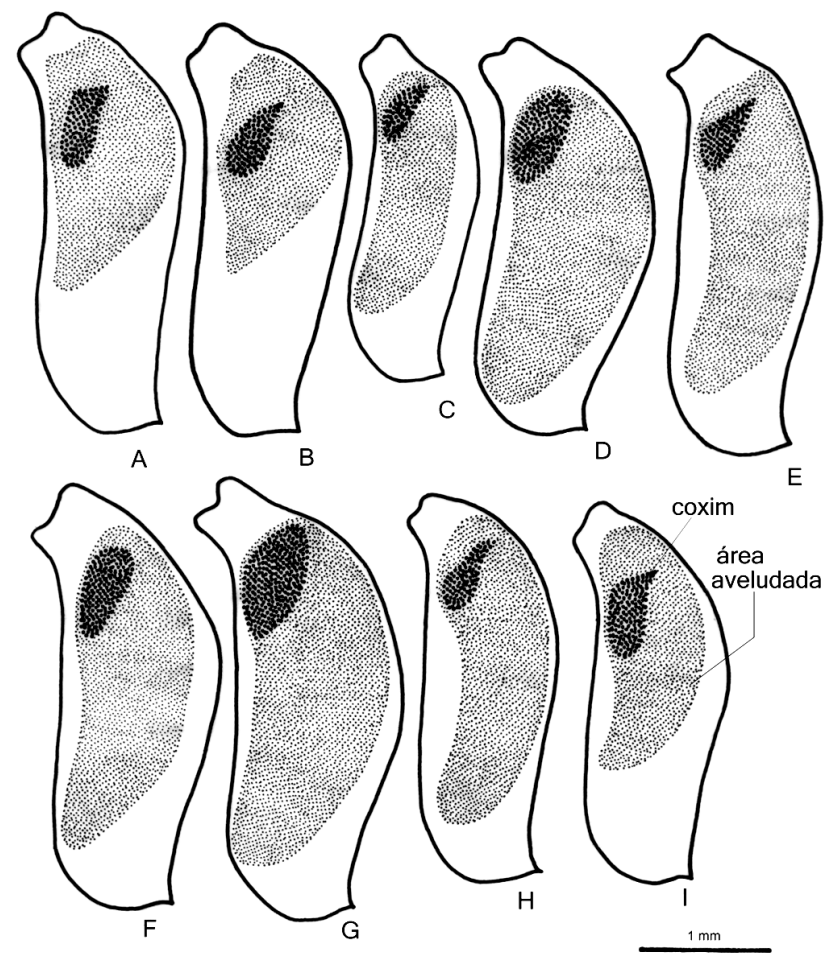

Figura 1 - Esboço da tíbia média de alguns machos de Eulaema com sua área aveludada e seu coxim. $\mathrm{A}=E$. leucopyga, $\mathrm{B}=E$. bomboides, $\mathrm{C}=E$. polychroma, $\mathrm{D}=E$. boliviensis, $\mathrm{E}=E$. napensis sp. n., $\mathrm{F}=$ E. pseudocingulata sp. $\mathrm{n} ., \mathrm{G}=$ E. cingulata, $\mathrm{H}=$ E. parapolyzona sp. n., $\mathrm{I}=$ E. polyzona. 
castanho-escuro, desprovido de reflexos metálicos, com exceção dos tergos V-VII de $E$. nigrita que são azul-violáceos; geralmente com manchas amareladas no clípeo e áreas paraoculares Subgênero Apeulaema

- Tegumento dos tergos com reflexos metálicos; geralmente sem manchas amareladas na face Subgênero Eulaema

\section{Subgênero Apeulaema}

1. Tegumento dos tergos metassomáticos preto, nos últimos azul-violáceo; pilosidade dos tergos I-IV preta, nos demais, preta misturada com amarela; asas bastante escuras [Costa Rica até sul do Brasil]. ..E. nigrita Lepeletier, 1841

- Tegumento dos tergos totalmente preto; pilosidade amarela na maioria dos tergos ou dividida em faixas amarelas e pretas.

2. Tergos metassomáticos II-VI inteiramente revestidos por pilosidade amarela.. .....3

- Tergos II-IV ou apenas o II com pilosidade dividida em faixas, pretas e amarelas..

.....4

3. Todos os tergos revestidos de pilosidade amarelo-clara a escura; área aveludada da tíbia média muito longa e larga como na figura 1d,g [Amazônia, Venezuela, Guianas e Parnaíba, Piauí].. E. mocsaryi (Friese, 1899)

- Apenas o tergo I, ou raramente este mais uma pequena parte do bordo anterior de tergo II revestido de pilosidade preta; nos demais, amarelo-clara a escuro; área aveludada da tíbia média longa e estreita (Fig. 1c) [Sudoeste dos Estados Unidos até norte da Venezuela e Peru, sempre nos Andes]......................................... polychroma (Mocsáry, 1899)

4. Pilosidade dos tergos II-IV dividida em faixas nítidas, preta basalmente e amarela apicalmente; área aveludada da tíbia média muito longa e larga (Fig. 1d) [Venezuela até Bolívia, sempre pelo oeste dos Andes] ........ E. boliviensis (Friese, 1898)

- Apenas a pilosidade do tergo II dividida em faixas, preta basalmente e amarela apicalmente, os demais inteiramente amarelos. ....5

5. Área aveludada da tíbia média, longa e larga, quase atingindo o bordo posterior da tíbia onde deixa uma estreita área lisa (Fig. 1g) [Noroeste do México até sul do Brasil]........... E. cingulata (Fabricius, 1804)

- Área aveludada longa e estreita, não alcançando o bordo posterior da tíbia e deixando uma ampla área lisa posteriormente (Fig. 1f) [Amazônia, Venezuela, Guianas e Trinidad \& Tobago] .........E. pseudocingulata sp. n.

\section{Subgênero Eulaema}

1. Pilosidade dos tergos metassomáticos I-III não dividida em faixas nítidas (podem ocorrer faixas claras interrompidas ou extremamente finas em $E$. terminata)

- Pilosidade dos tergos metassomáticos I-III dividida em faixas nítidas, claras e escuras
2. Pilosidade preta em todos os tergos (podendo ocorrer pilosidade clara somente nas laterais); língua muito longa, quando em repouso, atingindo o esterno $\mathrm{V}$ [Sudoeste da Colômbia até o noroeste do Equador, pela costa do Pacífico] E. sororia Dressler \& Ospina-Torres, 1997

- Pilosidade preta atingindo, no máximo, os quatro primeiros tergos; língua quando em repouso, atingindo o bordo anterior do esterno IV .................................................................. 3 3. Pilosidade preta apenas até os tergos I ou II ..................... 4 - Pilosidade preta apenas até os tergos III ou IV .................... 5 4. Pilosidade preta no tergo I (e às vezes porção basal do tergo II), nos demais variando de amarelo-clara a escuro [Costa Rica e norte da Venezuela, Brasil] ..........E. nigrifacies (Friese, 1898)

- Pilosidade dos tergos I e II escura, nos demais amarela a alaranjada [Costa Rica, norte da Venezuela e noroeste do Peru]............................................... E. speciosa (Mocsáry, 1897)

5. Pilosidade preta até o tergo IV (podendo ocorrer faixas extremamente finas ou interrompidas), nos demais amarelada [endêmica de Trinidad \& Tobago]...E. terminata (Smith, 1874) - Pilosidade preta somente até o tergo III .................................6 6- Pilosidade dos tergos metassomáticos I-III preta, nos demais amarelada; área aveludada da tíbia média, curta e larga, com extensa área lisa na porção distal (Fig. 1a) [Panamá até Equador pela vertente ocidental dos Andes]...E. leucopyga (Friese, 1898) - Pilosidade como na espécie anterior; área aveludada da tíbia média longa e estreita com pequena área lisa no ápice da tíbia (Fig. 1e) [bacia do rio Napo, Equador]............ napensis sp. n.

7. Apenas o tergo II com pilosidade dividida em faixas, preta basalmente e amarela distalmente; área aveludada da tíbia média curta e larga (Fig. 1b) [leste do Equador até noroeste do Peru]......................................... bomboides (Friese, 1923)

- Pilosidade dos tergos metassomáticos II e III sempre dividida

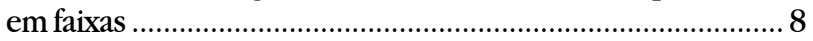

8. Pilosidade dos tergos II e III dividida em faixas claras basalmente e escuras distalmente ......................................... 9

- Pilosidade dos tergos II e III dividida em faixas, escuras basalmente e claras distalmente .............................................. 10

9. Pilosidade dos tergos metassomáticos IV-VII amarela a pálida [endêmica de Trinidad \& Tobago]........................................ E. basicincta Moure, 2000

- Pilosidade dos tergos IV-VII avermelhada [do Amapá-Brasil e Venezuela até Bolívia] ................... E. peruviana (Friese, 1903)

10. Esterno $\mathrm{V}$ liso, com alguns pêlos finíssimos apenas no bordo posterior, o qual é levemente convexo ....................... 11

- Esterno V inteiramente liso, com o bordo posterior praticamente reto; com pêlos grossos apenas no bordo posterior e nos laterais, ou totalmente coberto

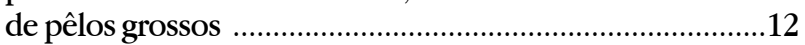

11. Área aveludada das tíbias médias relativamente longa e estreita (Fig. 1h) (alguns machos costumam trazer manchas amarelas na face) [Amazônia colombiana e boliviana, sem penetrar no Brasil] .............................. E. parapolyzona sp. n. 


\section{ACTA \\ AMAZONICA}

TRÊS NOVAS ESPÉCIES DE ABELHAS DA AMAZÔNIA PERTENCENTES AO GÊNERO Eulaema (HYMENOPTERA: APIDAE: EUGLOSSINI)
- Áreas aveludadas das tíbias médias mais curtas deixando ampla área lisa na porção distal das tíbias (Fig. 1i) [Amazônia brasileira até Guianas]

E. polyzona (Mocsáry, 1897)

12. Área aveludada das tíbias médias longa e estreitando-se para o ápice; bordo posterior do esterno $\mathrm{V}$ levemente côncavo.

. .13

- Área aveludada das tíbias médias curta e estreitando-se abruptamente para o ápice; bordo posterior do esterno $\mathrm{V}$ praticamente reto . 16

13. Abelhas de língua muito longa, atingindo quando em repouso o esterno VII; área aveludada longa e relativamente larga em toda sua extensão, deixando pouquíssima área lisa anterior e posteriormente [endêmica da província geográfica de Chocó, Colômbia]

E. chocoana Ospina-Torres \& Sandino-Franco, 1997

- Abelhas de língua não tão longa, atingindo no máximo o bordo posterior do esterno II; área aveludada longa e estreita, deixando áreas lisas na frente e atrás . . .14

14. Esterno V inteiramente revestido de pilosidade, como os demais esternos [Honduras até Amazônia e Mata Atlântica no Brasil, até o Rio de Janeiro] ...... E. bombiformis (Packard, 1869)

- Esterno V com pilosidade escassa, contratando com os demais esternos

.. 15

15. Faixas largas de pêlos amarelos nos bordos posteriores dos tergos I-IV (> 1,5 mm); pilosidade nos demais tergos alaranjada a vermelha [Guatemala até Amazônia, Guianas, Venezuela e Trinidad \& Tobago] ..........E. meriana (Olivier, 1789)

- Faixas muito estreitas de pêlos amarelo-limão nos bordos posteriores dos tergos I-IV (cerca de $1 \mathrm{~mm}$ ) [Venezuela e Brasil, da Paraíba ao Rio de Janeiro]...........E. flavescens (Friese, 1899)

16. Pilosidade dos tergos apicais, amarelada a esbranquiçada....17 - Pilosidade dos tergos apicais, alaranjada a avermelhada.....19 17. Faixa de pêlos esbranquiçados nos bordos posteriores dos tergos I-IV muito estreitas (até $1 \mathrm{~mm}$ ); pilosidade nos tergos apicais esbranquiçadas e com alguns pêlos marrons [endêmica de Trinidad \& Tobago] E. bennetti Moure, 1967

- Faixas de pêlos amarelados nos bordos posteriores dos tergos I-IV não tão estreitas como acima; pilosidade nos tergos apicais amarelada, ou amarelada com pêlos marrons ...18 18. Pilosidade nos últimos tergos amarelada [leste da Bolívia, Mato Grosso e Goiás no Brasil]. .E. helvola Moure, 2000
- Pilosidade nos últimos tergos amarelada, com alguns pêlos marrons [noroeste do México até norte da Venezuela e sudoeste da Colômbia, pela vertente ocidental dos Andes].

E. luteola Moure, 1967

19. Últimos tergos metassomáticos revestidos de pilosidade alaranjada [Bahia a São Paulo, na Mata Atlântica]. E. seabrai Moure, 1960

- Últimos tergos revestidos de pilosidade avermelhada [Amazônia até Guianas] E. tenuifasciata (Friese, 1925)

\section{AGRADECIMENTOS}

Aos curadores e colegas pelo empréstimo de material, aos dois consultores anônimos pelas críticas e sugestões.

\section{BIBLIOGRAFIA CITADA}

Dressler, R.L. 1979. Eulaema bombiformis, E. meriana, and müllerian mimicry in related species (Hymenoptera: Apidae). Biotropica, 11 (2): 144-151.

Moure, J.S. 1950. Contribuição para o conhecimento do gênero Eulaema Lepeletier (Hymen.- Apoidea). Dusenia, 1 (3): 181200.

Moure, J.S. 2000 [2003]. As espécies de Eulaema Lepeletier, 1841 (Hymenoptera, Apidae, Euglossinae). Acta Biol. Par., $29(1,2,3,4): 1-70$.

Oliveira, M.L. 2000. O gênero Eulaema Lepeletier, 1841(Hymenoptera: Apidae: Euglossini): filogenia, biogeografia e relações com as Orchidaceae. Tese de Doutorado. Faculdade de Filosofia, Ciência e Letras, USP, Ribeirão Preto, SP. 159pp.

Peruquetti, R.C.; Campos, L.A.O.; Coelho, C.D.P.; Abrantes, C.V.M.; Lisboa, L.C.O. 1999. Abelhas Euglossini (Apidae) de áreas de Mata Atlântica: abundância, riqueza e aspectos biológicos. Revista Brasileira de Zoologia, 16 (Suplemento 2): 101-118.

\author{
RECEBIDO EM 17/06/2004 \\ ACEITO EM 05/01/2006
}


